\title{
A Simple and Sensisitive HPLC Method to Monitor Serum and Synovial Fluid Concentrations of Ketorolac in Reumathologic Patients
}

\author{
Loretta Franceschi, Sara D'aronco and Mario Furlanut
}

Chair of Pharmacology, Institute of Clinical Pharmacology and Toxicology, DPMSC, University of Udine, Udine, Italy

\begin{abstract}
A rapid, selective and sensitive isocratic reversed-phase HPLC assay coupled with UV detection for quantification of ketorolac in serum and synovial fluid samples has been developed. Analytes were extracted on solid-phase cartridges (SPE) and chromatographic separation was achieved on a C18 column.

The chromatographic peak area ratio based on UV absorbency at $313 \mathrm{~nm}$ was used for quantitative analysis. This HPLC method has been successfully used for routine evaluation to monitor serum and synovial fluid concentrations in reumathologic patients affering to our institute. Thanks to its sensitivity, this HPLC/UV method is also suitable for pharmacokinetic studies.
\end{abstract}

Keywords: Ketorolac; HPLC; UV-VIS detection; Serum; Synovial fluid Introduction

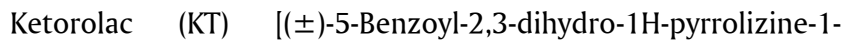
carboxylic acid] is a nonsteroidal anti-inflammatory drug (NSAID) with antipyretic and strong analgesic activity (Gillis and Brogden, 1997). As a pyrrolo-pyrrole, KT is chemically related to indomethacin and tolmetin. The onset and efficacy of analgesia after systemic administration are claimed to be comparable to that of morphine sulfate (O'Hara et al., 1987) and pethidine (Oosterlink et al., 1990), but KT causes less drowsiness, nausea, vomiting, and no abuse potential (Turturro et al., 1995). KT is administered orally, parenterally (IV, IM), or as an ophthalmic solution. Parenteral and oral dosages produce similar pharmacokinetic profiles. Absorption is rapid and complete; bioavalability is $100 \%$ after oral or IM administration. Peak serum concentrations after IM injection and oral administration are achieved within an hour. KT is more than $99 \%$ bound to albumin; crosses the placenta and is distributed into breast milk in small quantities. The mean elimination half-life of KT after IM or oral dosing is 5.3 hours. KT is metabolized through hydroxylation in the liver to form p-hydroxyketorolac and its metabolites are primarly excreted in the urine $(91 \%)$, and the remainder is eliminated in the feces.

KT, like other NSAIDs, are often used to alleviate pain and inflammatory processes (Colin, 2007). NSAIDs competitively inhibit both cyclooxygenase (COX) isoenzymes, COX-1 and COX2 (Warner and Mitchell, 2004), by blocking arachidonate binding. Anti-inflammatory and analgesic effects have been attributed to the inhibition of prostaglandin synthesis (Koay, 1996; Galan-Herera et al., 2008).

The aim of this study was to establish a simple and rapid high performance liquid chromatography (HPLC) method for identification and quantification of KT in serum and synovial fluid samples, to evaluate drug permeation. The assay was validated and applied to an in vivo study.

Though several chromatographic methods have been developed for the determination of KT by means of HPLC/UV or HPLC/mass spectrometry; some of these methods have a limit of quantification (LOQ) that is too high for evaluate permeation of KT in synovial fluid (Wang et al., 2001; Galan-Herera et al., 2008). Some are enantioselective (Nagilla et al., 2007; Nagilla et al., 2009) and require expensive chiral columns and length analysis times; some requires long time for treatment sample (Wu and Massey, 1990).

This report describes the optimisation and validation of an HPLC assay coupled with UV detection for quantification of KT. Sample handling and chromatographic run times were minimized to provide quantitative results while maintaining high sensitivity, specificity, accuracy and precision for the pharmacokinetic evaluation of KT. In view of these applications the method, was tested on samples obtained from rheumatic patients.

\section{Material and Methods}

\section{Reagents and extraction sorbent}

Ketorolac and ketoprofen (KTP) (internal standard) were purchased from Sigma-Aldrich (Milan, Italy).

All solvents were HPLC grade: acetonitrile, isopropilic alcohol, and formic acid were purchased from Merck (Darmstadt, Germany); methanol from Carlo Erba (Milan, Italy); potassium phosphate and sodium acetate from Sigma-Aldrich (Steinheim, Germany). Water was deionised, and purified on a Milli-Q Plus Reagent Grade Water System (Millipore, USA).

The solid-phase extraction (SPE) cartridges Isolute C18 (EC) containing $200 \mathrm{mg}$ of stationary phase and with a volume of $3 \mathrm{~mL}$ were purchased from StepBio (Bologna, Italy).

\section{Chromatographic conditions}

The HPLC system consisted of a model 126 solvent delivery unit (Beckman Instruments, Berkeley, CA) a model LC 295 UV-VIS (Perkin

*Corresponding author: Loretta Franceschi, Chair of Pharmacology, Institute of Clinical Pharmacology and Toxicology, DPMSC,University of Udine, Piazzale SM della Misericordia 15, 33100 Udine - Italy, Tel: +39 (0)432 559833; Fax: +39 (0)432 559819; E-mail: loretta.franceschi@uniud.it

Received August 26, 2010; Accepted October 12, 2010; Published October 12 2010

Citation: Franceschi L, D'aronco S, Furlanut M (2010) A Simple and Sensisitive HPLC Method to Monitor Serum and Synovial Fluid Concentrations of Ketorolac in Reumathologic Patients. J Bioanal Biomed 2: 121-124. doi:10.4172/1948$593 \times .1000034$

Copyright: ( 2010 Franceschi L, et al. This is an open-access article distributed under the terms of the Creative Commons Attribution License, which permits unrestricted use, distribution, and reproduction in any medium, provided the original author and source are credited. 
Elmer, USA), set at $313 \mathrm{~nm}$, connected by a model 406 interface unit (Beckman Instruments, Berkeley, CA) to a chromatography workstation System Gold (version 6) (Beckman Instruments, Berkeley, CA)

Chromatographic separation was performed with a Beckman C18 column (ODS-250 mm x $2.1 \mathrm{~mm}-5 \mu \mathrm{m}$ ); a guard column LichroCART 4-4 RP-18 (Merck, Darmstadt, Germany) was connected to protect the analytical column. The mobile phase was a mixture of methanol/ acetonitrile/isopropilic alcohol/phosphate buffer (0.02M) (10/25/5/60 $\mathrm{v} / \mathrm{v}$ ), degassed with an ultrasonic bath Branson (USA). Flow rate was set at $0.2 \mathrm{~mL} / \mathrm{min}$. Total run time was less than 12 min for each injection.

\section{Preparation of stock and work solutions}

Stock solutions of KT and KTP were prepared separately in methanol acidified with formic acid $(0.1 \%)$ at the concentration of 1 $\mathrm{mg} / \mathrm{mL}$. Working solutions, for the preparation of calibration curves and quality control samples, were made by diluting, in methanol, stock solutions. Stock and work solutions were stored at $-80^{\circ} \mathrm{C}$.

\section{Sample preparation}

We combined $500 \mu \mathrm{l}$ of serum or synovial fluid with $5 \mu \mathrm{l}$ of IS, KTP (100 ng/ $\mu \mathrm{l}$ and $100 \mu \mathrm{l}$ of sodium acetate $0.5 \mathrm{M} \mathrm{(pH} \mathrm{3).} \mathrm{After} \mathrm{mixing,}$ the sample was transferred into an extraction cartridge conditioned with $3 \mathrm{~mL}$ of methanol and then $3 \mathrm{~mL}$ of water. After washing the extraction cartridge with $3 \mathrm{~mL}$ of water, the sample was eluted with $3 \mathrm{~mL}$ of methanol. After evaporation of the organic phase, under a nitrogen stream at $40^{\circ} \mathrm{C}$, the residue was dissolved with $100 \mu \mathrm{l}$ of mobile phase and $20 \mu \mathrm{l}$ was injected into the HPLC system.

\section{Calibrators and quality control samples}

Calibrators and quality control samples (QC) containing KT were prepared adding known amounts of analyte to blank serum and synovial fluid. They were included in each batch of patient samples.

\section{Pharmacokinetic validation}

The analytical method was applied to real serum and synovial samples: after approval by the Ethics Committee of the Policlinico Universitario of the University of Udine and after obtaining informed consent, 20 rheumatic patients who had a synovial fluid sample for diagnostic purpose and were candidates to KT treatment, were prospectively admitted to the study; all patients received $30 \mathrm{mg}$ of KT by IM administration. Each patient had only 1 blood and 1 synovial fluid sample. To obtain Area Under the Curve (AUC) values (calculated by means of trapezoidal rule) and to evaluate KT diffusion into knee articular fluid, blood and synovial fluid samples were collected, before KT administration, and 0.5, 1, 1.5, 2, 3, 4, 6, 7, and 8 hours following its administration. Blood samples were centrifuged at $3000 \mathrm{rpm}$ for 10 minutes. Serum and synovial fluid samples were transferred to polypropylene tubes and frozen in liquid nitrogen until processing.

\section{Results}

\section{Selectivity and specificity}

We obtained a reliable separation of ketorolac and IS using the chromatographic conditions reported above. Chromatographic performance was good for both compounds with good peak shapes and acceptable retention times for routine activity. In an interference study, blank serum and synovial fluid samples were prepared as described above to check for peaks that might interfere with detection of ketorolac and IS. All samples gave chromatograms free of peaks co-eluting with ketorolac or IS (Figure 1 and Figure 2).

\section{Calibration and linearity}

Aliquots of blank plasma or synovial fluid $(500 \mu \mathrm{L})$ were enriched with ketorolac to obtain calibration samples ranged from 50 to 2000 $\mathrm{ng} / \mathrm{mL}$. Calibration curves were obtained by fitting the peak area ratios of ketorolac vs the internal standard with a linear regression model. Correlation coefficients, respectively for serum and synovial fluid, were 0.997 and 0.999 (Figure 3).

Daily calibration samples were prepared and analyzed with each batch of validations and/or authentic samples.

Linearity and limit of linearity (LOL), defined as the concentration at which the calibration curve departs from linearity, were evaluated analyzing quality control samples with concentration lower and greater than range of calibration curves.

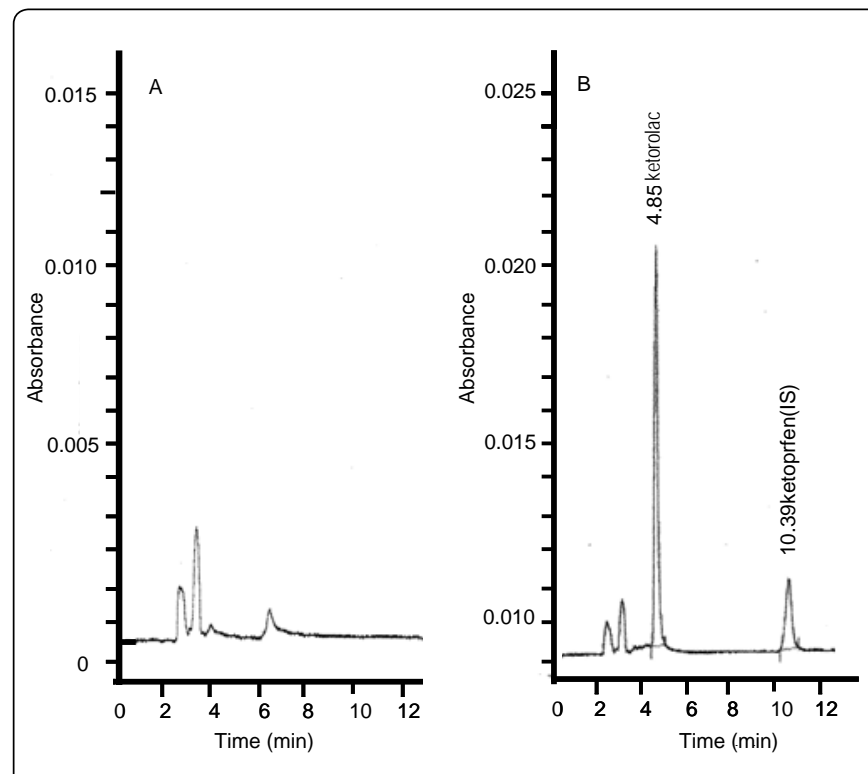

Figure 1: Chromatogram of drug-free serum (A) and serum sample (1879 ng/ $\mathrm{ml}$ ) from patient treated with ketorolac (30 $\mathrm{mg} \mathrm{IM})$.

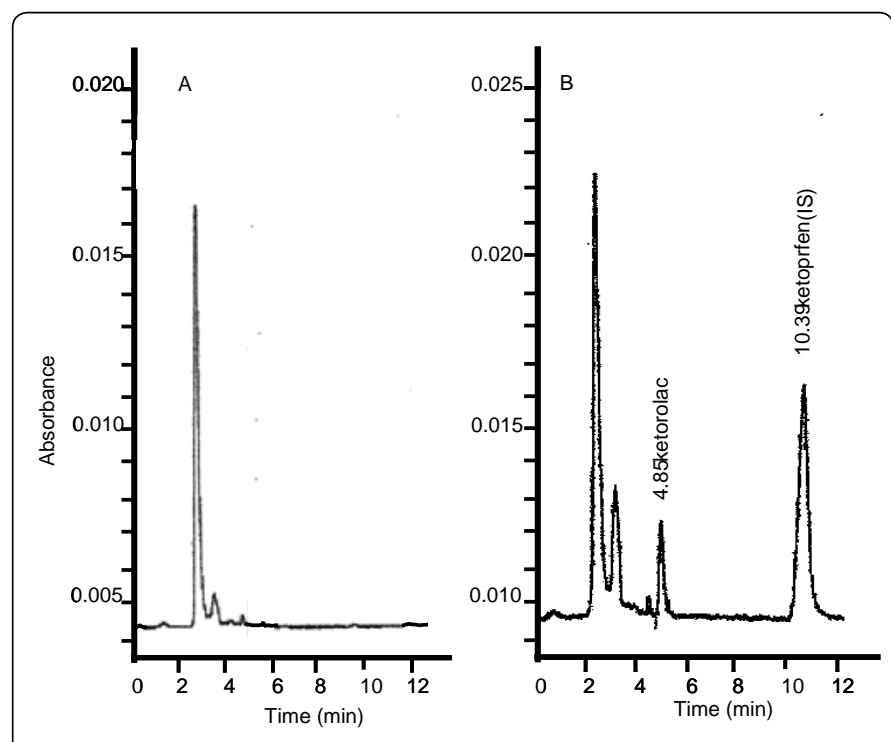

Figure 2: Chromatogram of drug-free synovial fluid $(A)$ and synovial fluid sample $(205 \mathrm{ng} / \mathrm{ml})$ from patient treated with ketorolac (30 $\mathrm{mg} \mathrm{IM})$. 
The lower (LLOL) and the upper LOL (ULOL) were respectively, 20 and $3200 \mathrm{ng} / \mathrm{mL}$, both for serum and synovial fluid.

\section{Recovery}

The extraction recovery was determined comparing the analyteto-IS ratios in QC prepared in drug-free human serum and synovial fluid and reconstituted in the mobile phase and QC prepared in the mobile phase directly. The extraction recoveries, estimated at five different concentrations, ranged from 92.23 to $95.16 \%$ (93.38 \pm 1.46 (mean \pm SD) and from 90.65 to $94.40 \%(92.26 \pm 1.746$ (mean \pm SD) respectively for serum and synovial fluid.

\section{Limit of quantification and detection}

The sensitivity of the method was evaluated by determining the lower limit of quantification (LLOQ) and the limit of detection (LOD). The LLOQ was selected as the LLOL $(20 \mathrm{ng} / \mathrm{ml})$ while LOD $(5 \mathrm{ng} / \mathrm{ml})$ was defined as the concentration with a signal-to-noise $(\mathrm{S} / \mathrm{N})$ ratio of at least three.
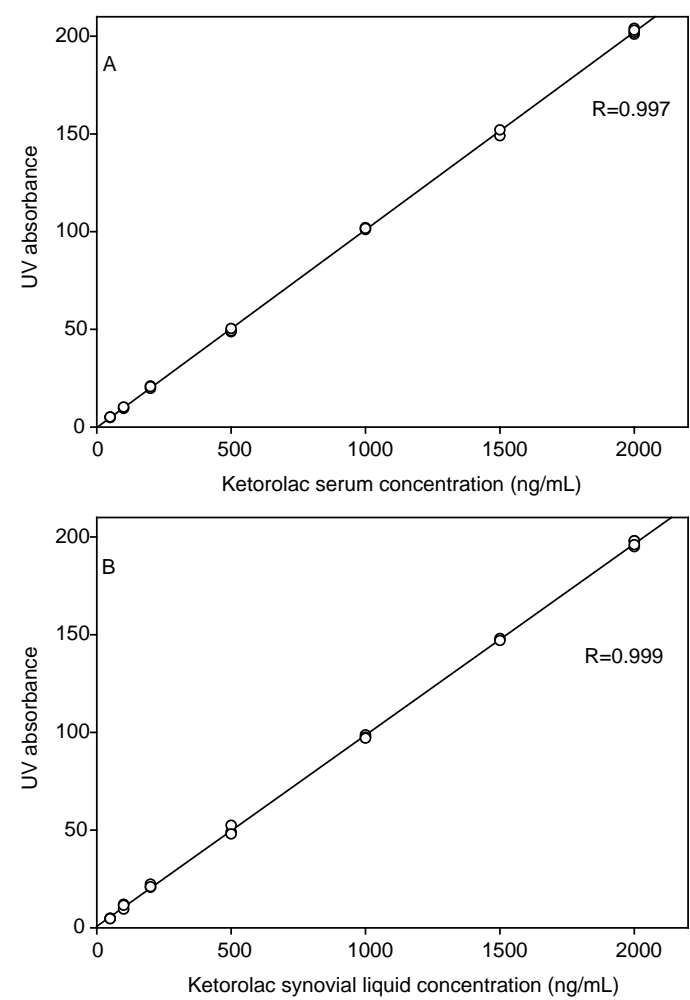

Figure 3: Calibration curve of ketorolac for serum (A) and synovial fluid (B)

\begin{tabular}{|c|c|c|c|c|}
\hline & \multicolumn{2}{|c|}{ Intra-day $(\mathrm{n}=4)$} & \multicolumn{2}{c|}{ Inter-day $(\mathrm{n}=5)$} \\
\hline $\begin{array}{c}\text { Concentration } \\
(\mathrm{ng} / \mathrm{mL})\end{array}$ & Serum sample & $\begin{array}{c}\text { Synovial fluid } \\
\text { sample }\end{array}$ & Serum sample & $\begin{array}{c}\text { Synovial fluid } \\
\text { sample }\end{array}$ \\
\hline & $\begin{array}{c}\text { Obtained } \\
\text { (mean } \pm \mathrm{SD})\end{array}$ & $\begin{array}{c}\text { Obtained } \\
(\text { mean } \pm \mathrm{SD})\end{array}$ & $\begin{array}{c}\text { Obtained } \\
\text { (mean } \pm \mathrm{SD})\end{array}$ & $\begin{array}{c}\text { Obtained } \\
(\text { mean } \pm \mathrm{SD})\end{array}$ \\
\hline 30 & $29.00 \pm 1.29$ & $29.50 \pm 1.29$ & $29.00 \pm 0.82$ & $29.25 \pm 1.26$ \\
\hline 50 & $49.20 \pm 2.06$ & $49.50 \pm 1.00$ & $49.75 \pm 2.22$ & $49.51 \pm 2.38$ \\
\hline 100 & $98.75 \pm 2.22$ & $99.00 \pm 0.82$ & $100.25 \pm 2.06$ & $99.15 \pm 0.91$ \\
\hline 200 & $200.75 \pm 1.26$ & $197.50 \pm 9.57$ & $199.25 \pm 1.89$ & $195.25 \pm 9.74$ \\
\hline 500 & $499.25 \pm 2.75$ & $497.50 \pm 20.61$ & $500.25 \pm 3.30$ & $496.00 \pm 7.62$ \\
\hline 1000 & $1006.50 \pm 10.66$ & $994.75 \pm 19.06$ & $1015.00 \pm 1915$ & $986.00 \pm 6.97$ \\
\hline 1500 & $1498.25 \pm 11.14$ & $1480.00 \pm 8.17$ & $1509 \pm 12.15$ & $1496.25 \pm 10.40$ \\
\hline 2000 & $2000.75 \pm 3.86$ & $1885.00 \pm 81.85$ & $2011.75 \pm 19.62$ & $1993.25 \pm 17.29$ \\
\hline 2500 & $2498.50 \pm 7.416$ & $2470.00 \pm 14.14$ & $1497.75 \pm 11.79$ & $2497.75 \pm 17.69$ \\
\hline 3000 & $2997.50 \pm 7.59$ & $2908.25 \pm 53.56$ & $2997.50 \pm 14.53$ & $3011.25 \pm 29.41$ \\
\hline
\end{tabular}

Table 1: Intra- and inter day precision.

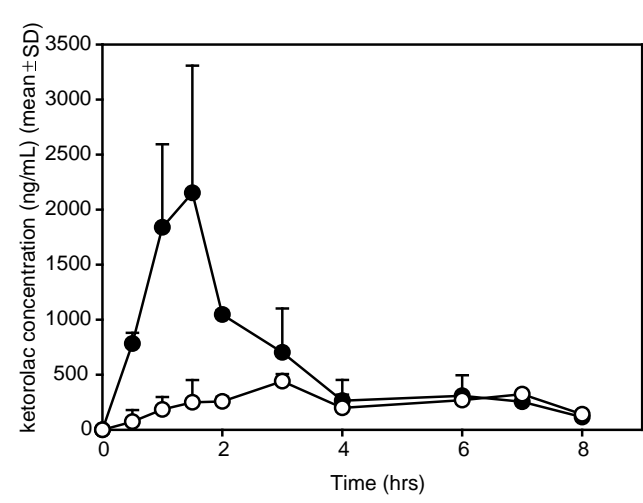

Figure 4: The mean $( \pm \mathrm{SD})$ serum $(\bullet-\bullet)$ and synovial fluid $(\mathbf{O}-\mathbf{0})$ concentrations of ketorolac in 20 rheumatic patients (30 mg IM).

\section{Intra and inter assay}

A series of QC samples were prepared at 10 different concentrations in the range of $30-3000 \mathrm{ng} / \mathrm{mL}$. Intra-day precision was calculated after four replicate runs of the same extracted sample; inter-day precision was calculated after extraction and analysis on 5 consecutive days (Table 1).

\section{Serum and synovial fluid concentrations}

Mean $( \pm \mathrm{SD})$ peak serum and synovial fluid concentrations $\left(\mathrm{C}_{\max }\right)$ were $2152.40( \pm 350.2)$ and $441.38( \pm 65.24) \mathrm{ng} / \mathrm{mL}$ respectively. Serum and synovial fluid $T_{\text {max }}$ were 1.5 and 3 hours respectively. Mean ( $\pm \mathrm{SD}$ ) serum and synovial fluid concentrations after IM dose $(30 \mathrm{mg})$ of ketorolac are shown in Figure 4.

Serum and synovial fluid $\mathrm{AUC}_{0-\infty}$ resulted $5885.90 \mathrm{ng} / \mathrm{mL} \mathrm{h}$ and $2152.00 \mathrm{ng} / \mathrm{mL}$ h respectively.

\section{Discussion}

The aim of this investigation was the implementation of an HPLCUV method for the quantification of ketorolac in serum and synovial fluid samples of rheumatic patients. The proposed chromatographic procedure provides good results for the determination of ketorolac in serum and synovial fluid in terms of selectivity, specificity, linearity, LLOQ and LOD, recovery and reproducibility. We decided to use a chromatographic column with an internal diameter of 2.1 $\mathrm{mm}$ to cut down on mobile phase. This method seems to be more sensitive than those reported previously (LLOQ $20 \mathrm{ng} / \mathrm{ml}$ and LOD $5 \mathrm{ng} / \mathrm{ml}$ ) (Oosterlink et al., 1990; Turturro et al., 1995). This means that the proposed procedure is useful for pharmacokinetic studies and to evaluate KT diffusion into synovial fluid. Preliminary results, on a limited number of rheumatic patients, demonstrated that KT concentrations in the synovial fluid reach their maximum levels $\left(\mathrm{C}_{\max }\right)$ more slowly than in the serum ( $3 \mathrm{hrs}$ vs $1.5 \mathrm{hrs}$ ), and are more than 5 times lower than those in the serum. Furthermore serum KT concentrations decrease very rapidly by reaching quite similar synovial fluid concentrations after 4 hrs of drug IM administration.

The method, thanks to its rapid extraction procedure and short retention time, is also suitable also TDM of patients treated with ketorolac. We choose SPE for sample pre-treatment because this technique allows to obtain both a high recovery rate and cleaner samples than the liquid-liquid extraction.

After several months of routine evaluation of this method in our laboratory, we concluded that it is useful for TDM. By using this 
Citation: Franceschi L, D'aronco S, Furlanut M (2010) A Simple and Sensisitive HPLC Method to Monitor Serum and Synovial Fluid Concentrations of Ketorolac in Reumathologic Patients. J Bioanal Biomed 2: 121-124. doi:10.4172/1948-593X.1000034

procedure, the extraction requires less than $30 \mathrm{~min}$, chromatographic separation takes $12 \mathrm{~min}$ only and the chromatographic system presents a long-term stability.

\section{References}

1. Colin $\mathrm{J}$ (2007) The role of NSAIDs in the management of postoperative ophthalmic inflammation. Drugs 67: 1291-1308.

2. Galán-Herrera JF, Poo JL, Maya-Barrios JA, de Lago A, Oliva I, et al. (2008) Bioavailability of two sublingual formulations of ketorolac tromethamine $30 \mathrm{mg}$ a randomized, open-label, single-dose, two-period crossover comparison in healthy Mexican adult volunteers. Clin Ther 30: 1667-1674.

3. Gillis JC, Brogden RN (1997) Ketorolac. A reappraisal of its pharmacodynamic and pharmacokinetic properties and therapeutic use in pain management. Drugs 53: 139-188.

4. Koay $P$ (1996) The emerging roles of topical non-steriodal anti-inflammatory agents in ophthalmology. Br J Ophthalmol 80: 480-485.

5. Nagilla R, Deshmukh DD, Copedge KJ, Miller S, Martin B, et al., (2009) Enantiomeric disposition of ketorolac in goats following administration of a single intravenous and oral dose. J Vet Pharmacol Ther. 32: 49-55.
6. Nagilla R, Deshmukh DD, Duran SH, Ravis WR (2007) Stereoselective pharmacokinetics of ketorolac in calves after a single intravenous and oral dose. J Vet Pharmacol Ther 30: 437-442.

7. O'Hara DA, Fragen RJ, Kinzer M, Pemberton D (1987) Ketorolac tromethamine as compared with morphine sulfate for treatment of postoperative pain. Clin Pharmacol Ther 41: 556-561.

8. Oosterlink W, Philip NH, Charig C, Gillies G, Hetherington JW, et al. (1990) A double-blind single dose comparison of intramuscular ketorolac trometamine and pethidine in the treatment of renal colic. J Clin Pharmacol 30: 336-341.

9. Turturro MA, Paris PM, Seaberg DC (1995) Intramuscolar ketorolac versus oral ibuprofene in acute musculoskeletal pain. Ann Emerg Med 26: 117-120.

10. Wang Z, Dsida RM, Avram MJ (2001) Determination of ketorolac in human plasma by reversed-phase high-performance liquid chromatography using solid-phase extraction and ultraviolet detection. J Chromatogr B Biomed Sci Appl 755: 383-386.

11. Warner TD, Mitchell JA (2004) Cyclooxygenases: new forms, new inhibitors, and lessons from the clinic. FASEB J 18: 790-804.

12. Wu AT, Massey IJ (1990) Simultaneous determination of ketorolac and its hydroxylated metabolite in plasma by high-performance liquid chromatography. J Chromatogr 534: 241-246. 